Fábio José Rodrigues da Costa (URCA)

\title{
SOBRE SER ARTISTA/PROFESSOR/ PESQUISADOR CONTEMPORÂNEO
}
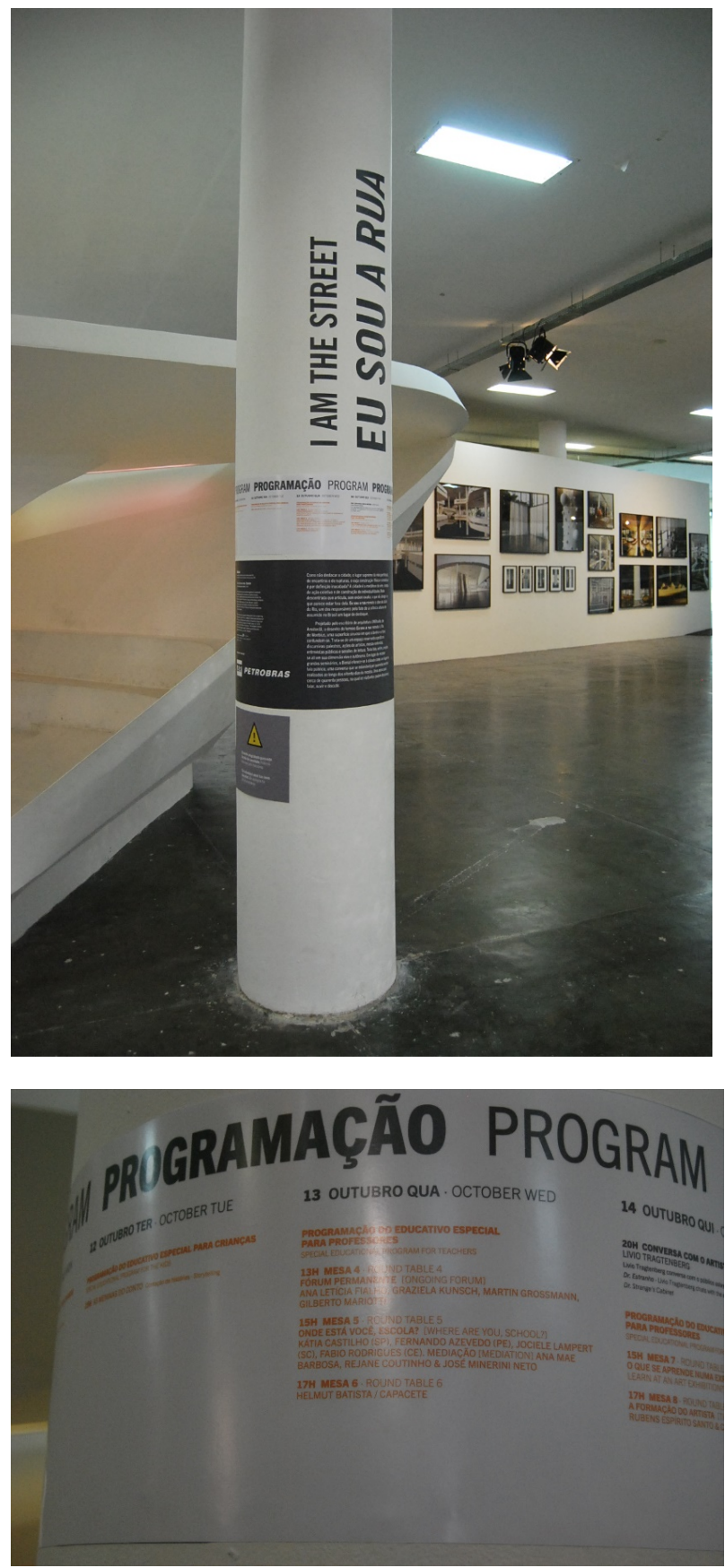

Em 2005 recebi de Ana Mae Barbosa o livro A Formação do Professor e o Ensino das Artes Visuais, organizado por Marilda Oliveira de Oliveira e Fernando Hernández, publicado pela Editora da Universidade Federal de Santa Maria (editoraufsm). Nesta época estava em Sevilla/Espanha cursando meu doutorado e gozava do privilégio de ser bolsista de doutorado pleno no exterior pelo Conselho Nacional de Desenvolvimento Científico e Tecnológico CNPq. Foi o livro quem me apresentou a Jociele Lampert já que não era um des coautords e sim mencionado na Introdução por Ana Mae. No entanto, li o artigo da Jociele Lampert e logo incorporei suas ideias a minha tese "Didática do Ensino das Artes Visuais: uma proposição pós-moderna" defendida em 2007. Cinco anos depois, tive a oportunidade de conhecer a Jociele Lampert em um momento muito especial porque se tratava de participar de uma mesa com ela na 29 Bienal de São Paulo (2010). Infelizmente, a agenda em São Paulo não permitiu uma aproximação mais 

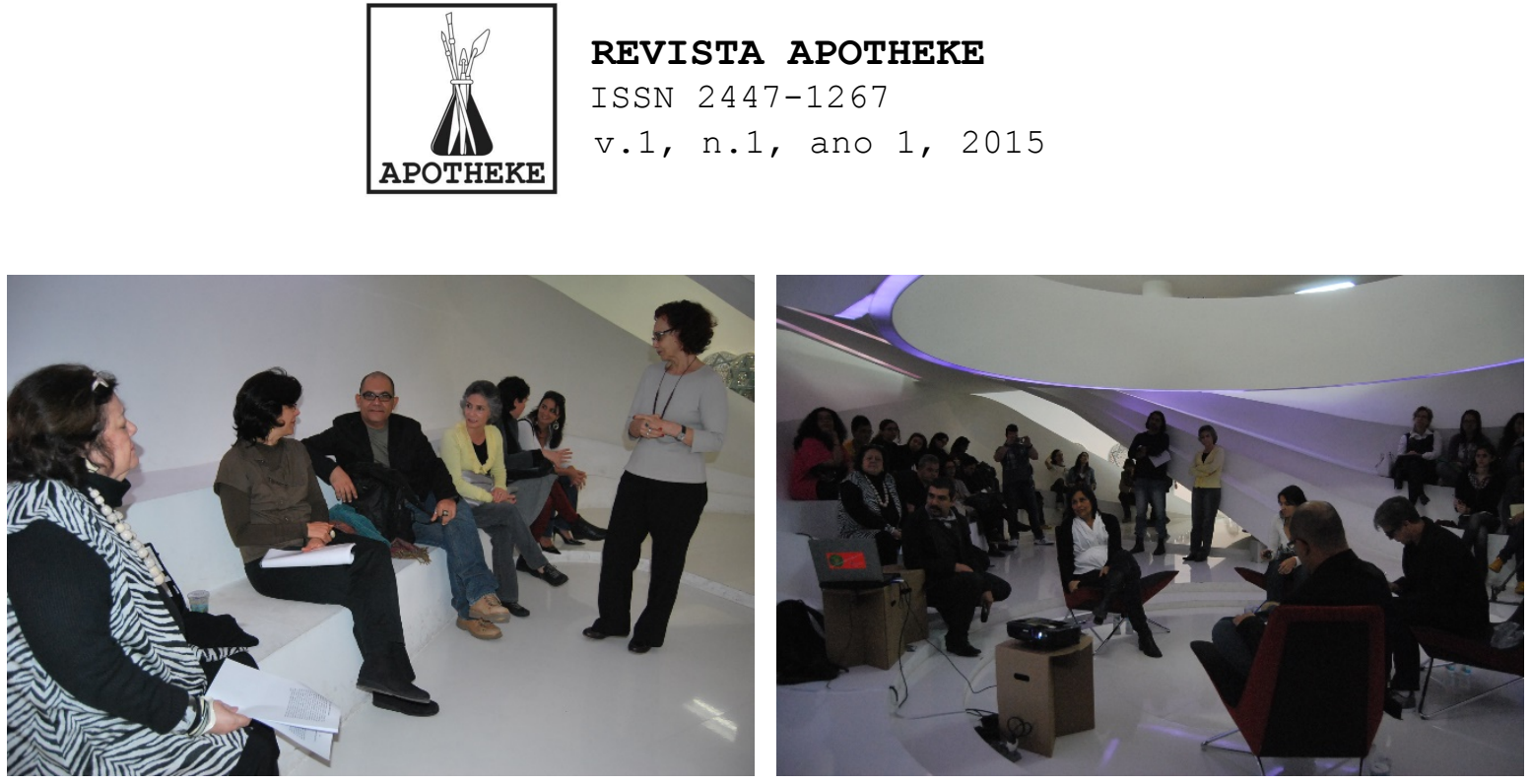

significativa com a Jociele, e, querendo ou não, estávamos em um não-lugar. E aliás, parece que alguns de nós necessita desses não-lugares para encontrar ou reencontrar parceiras de caminhada.

Em 2013 chegou o momento de visitar Nova York já que havia optado por realizar o doutorado na Europa e não nos Estados

Unidos e desde 2005

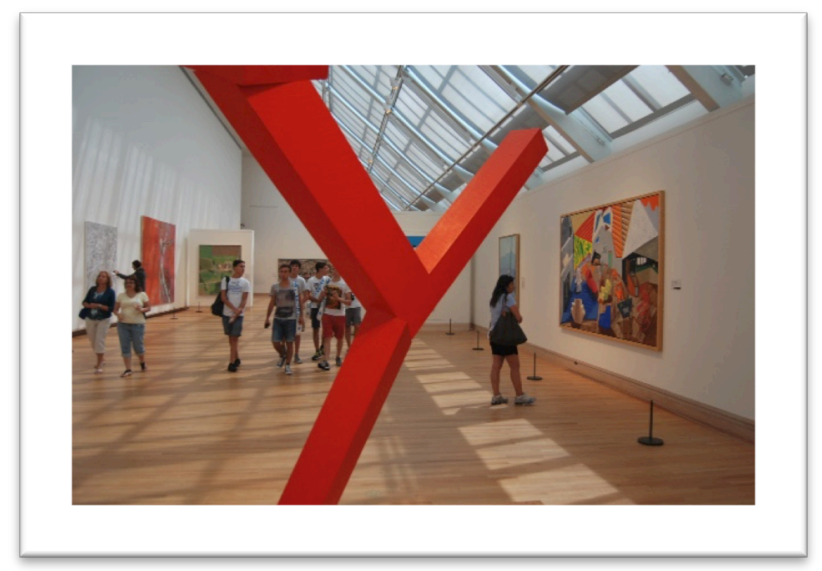

planejava conhecer este país e, principalmente, me aproximar da relação entre arte, gay e cultura queer. Minha primeira aproximação ao tema ocorreu em 2012 quando orientei o trabalho de conclusão de curso de José Jaildo da Silva Oliveira intitulado Diálogos entre as Produções Artísticas Visuais Gays e o Ensino da Arte: uma contribuição para uma escola sem homofobia. Durante nossos encontros nos dávamos conta de que a bibliografia no Brasil não era suficientemente voltada para as artes visuais, mas que em outros países e, nos Estados Unidos em particular, sabíamos da existência de uma vasta bibliografia além de museus, centros culturais e galerias

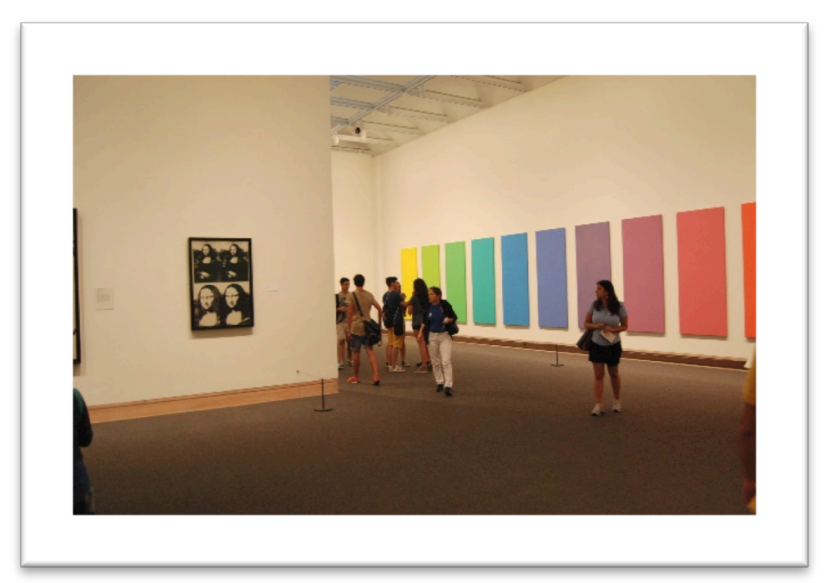
que exibiam a produção de artistas gays e militantes do movimento LGBTT.

Foi em Nova York que reencontrei Jociele Lampert e lá com ela andei, comi, vi, senti, escutei, acompanhei e vislumbrei ações colaborativas. 


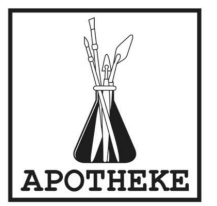

REVISTA APOTHEKE

ISSN 2447-1267

v.1, n.1, ano 1, 2015

Retornando de Nova York dei início aos preparativos da I Semana de Artes Visuais que ocorreria em setembro de 2013. Ao mesmo tempo a Jociele sugeriu que eu recebesse um de seus orientandos do Programa de Mestrado em Artes Visuais da UDESC que viria para uma residência, um tempo para conversas e arqueologias. Assim recebi no Centro de Artes e no Grupo de Pesquisa Ensino da Arte em Contextos Contemporâneos - GPEACC/CNPq do Centro de Artes da Universidade Regional do Cariri - URCA O Fábio Wosniak para uma semana de residência, de 23 a 28.
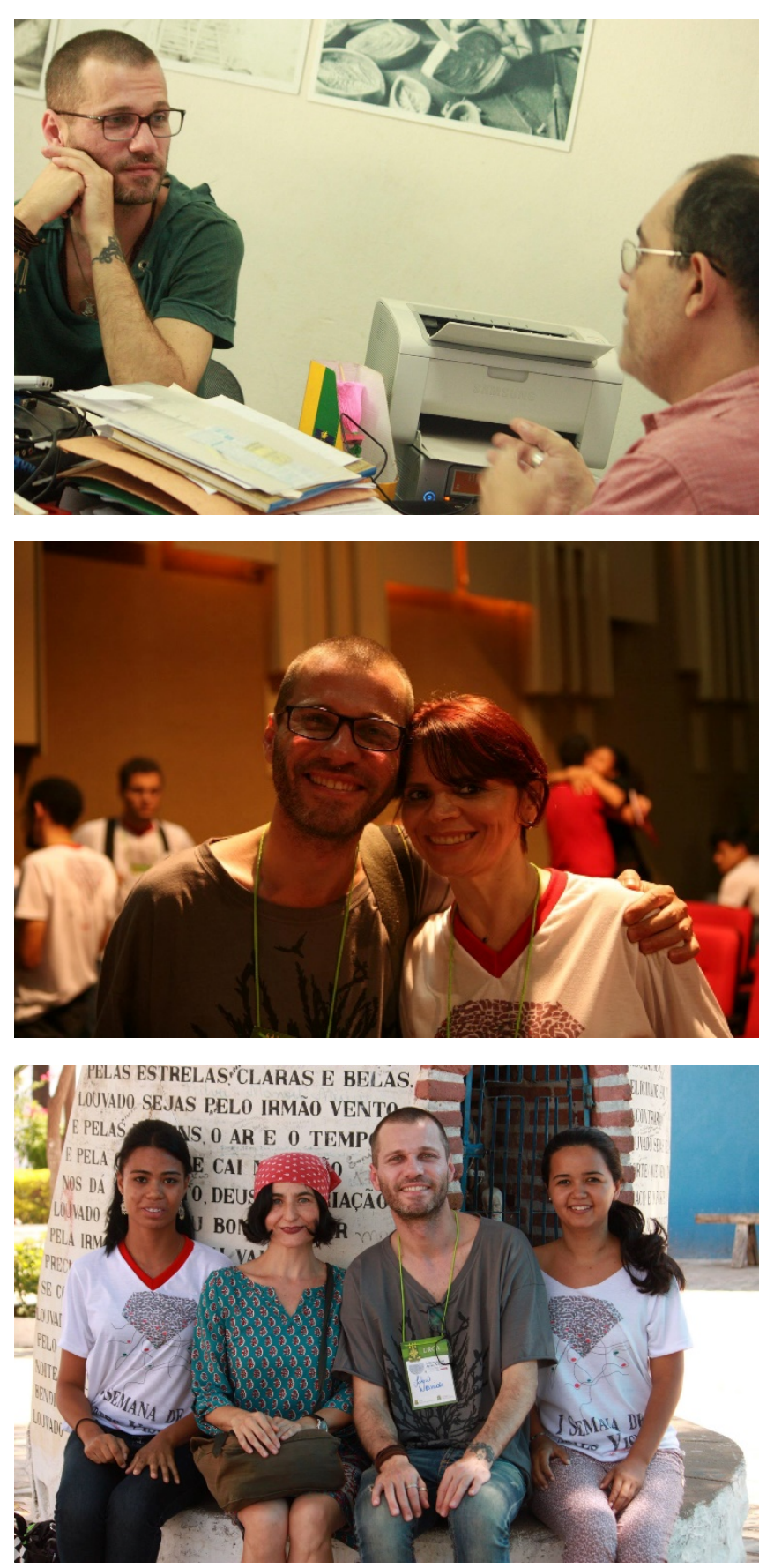

Não sabia ao certo como seria a residência para o Fábio Wosniak, mas para mim seria a oportunidade para tratarmos de sua pesquisa, da vida, da pesquisa de novo e da vida. A I Semana de Artes Visuais receberia além do Fábio Wosniak o Dr. José Paiva da Faculdade de Belas Artes da Universidade do Porto - Portugal, a Dra. Pilar Perez da Universidade Autonoma de Madrid - Espanha, a Dra. Rejane Coutinho do Instituto de Artes da UNESP - São Paulo, a Dra. Vitória Amaral Negreiros do Centro de Artes e comunicação CAC da UFPE e a Dra. Lucimar Bello Frange, artista/professora/pes quisadora aposentada da UFU.

A residência, a I Semana de Artes Visuais, nossos convidados e toda a comunidade do Centro 


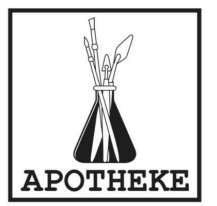

REVISTA APOTHEKE

ISSN 2447-1267

$\mathrm{v} .1, \mathrm{n} .1$, ano 1,2015

de Artes deram os contornos para mais um encontro com a Jociele Lampert em maio de 2014, agora ela viria ao Centro de Artes da URCA como nossa convidada para participar do 3ei_ea. Não viria só porque o Fábio Wosniak também participaria do evento.

O 3ei ea ocorreu nos dias 05, 06 e 07 de maio de 2014 dando continuidade aos Encontros Internacionais ocorridos em Cabo Verde - 2010 e Portugal - 2012. A Jociele Lampert como nossa convidada fez parte do Comitê Científico do evento e conviveu com todos os nossos convidados: Dr. José Paiva Portugal, Dr. Ramón Cabrera - Cuba, Dra. Ángeles Saura Espanha, Dr. Leão Lopes - Cabo Verde, Dra. Ethel Batres Guatemala, Dr. Carlos Falci - UFMG, Dr. Milton Sogabe UNESP, Dra. Vitória Amaral - UFPE, Dr. Adilson Florentino UNIRIO, Dra. Rejane Coutinho - UNESP, Dra. Lêda Guimarães UFG, Dra. Rosa Gadelha - UFC, Dra. Graziela Rodrigues UNICAMP, Dra. Carla Lima - UFU, Dra. Cristiane Almeida UFPE, Dra. Lucimar Bello Frange - UFU, Dra. Lívia Marques Carvalho - UFPB, Dra. Ana Mae Barbosa - USP, além dos mais de 500 participantes de todas as regiões do Brasil.

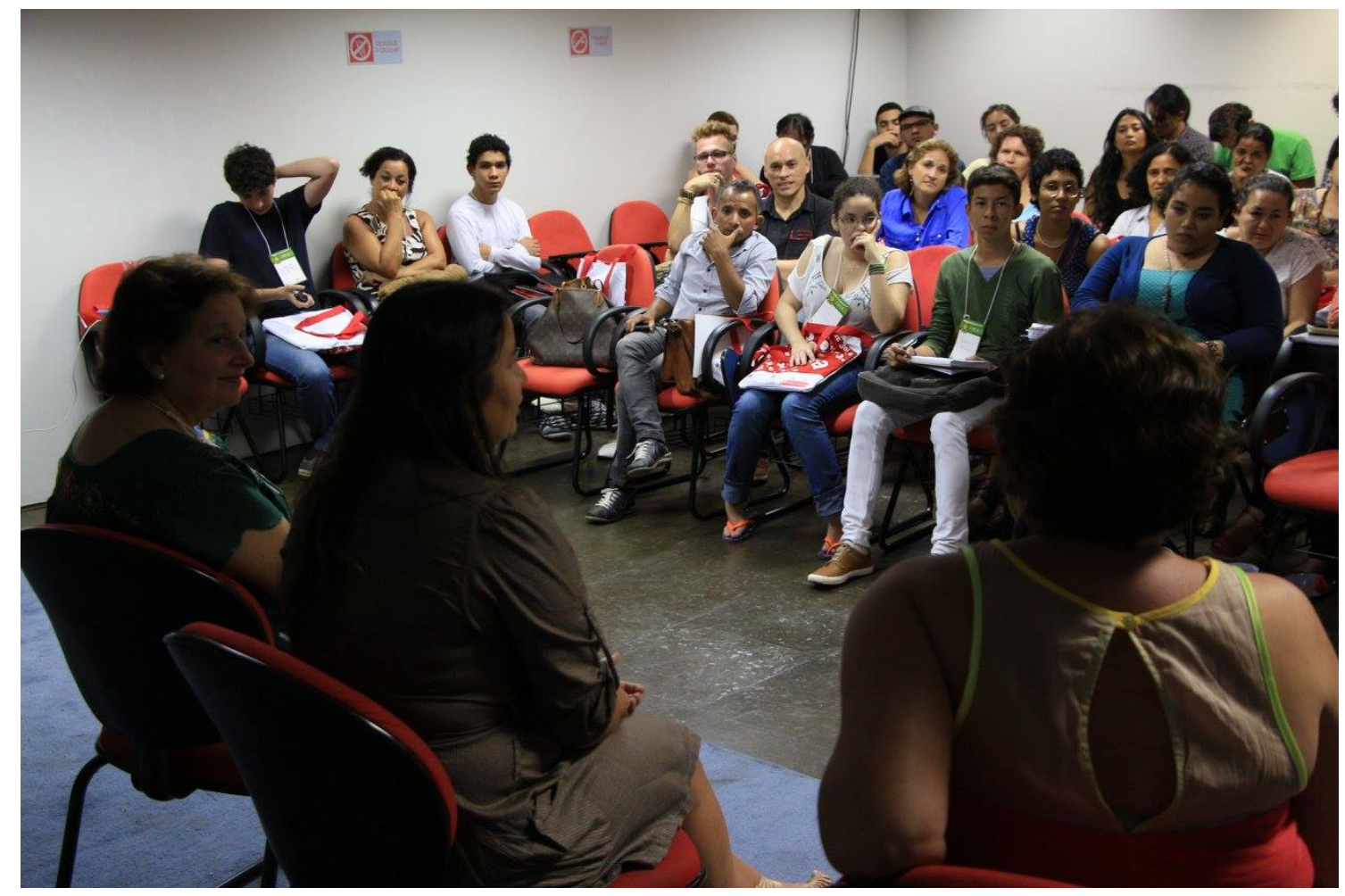

Em dezembro de 2014 novamente me encontro com Jociele Lampert e Fábio Wosniak, mas agora iria participar como membro avaliador da Qualificação do Fábio que ocorreria na UDESC/Florianópolis. Já tinha estado em Florianópolis em 


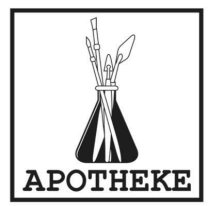

\section{REVISTA APOTHEKE}

ISSN 2447-1267

$\mathrm{v} .1, \mathrm{n} .1$, ano 1,2015

2007 para participar do $17^{\circ}$ CONFAEB, então era um retorno. Também iria reencontrar com Lucimar Bello e conhecer Maria Lúcia Batezar Duarte que comigo integravam a banca de qualificação.

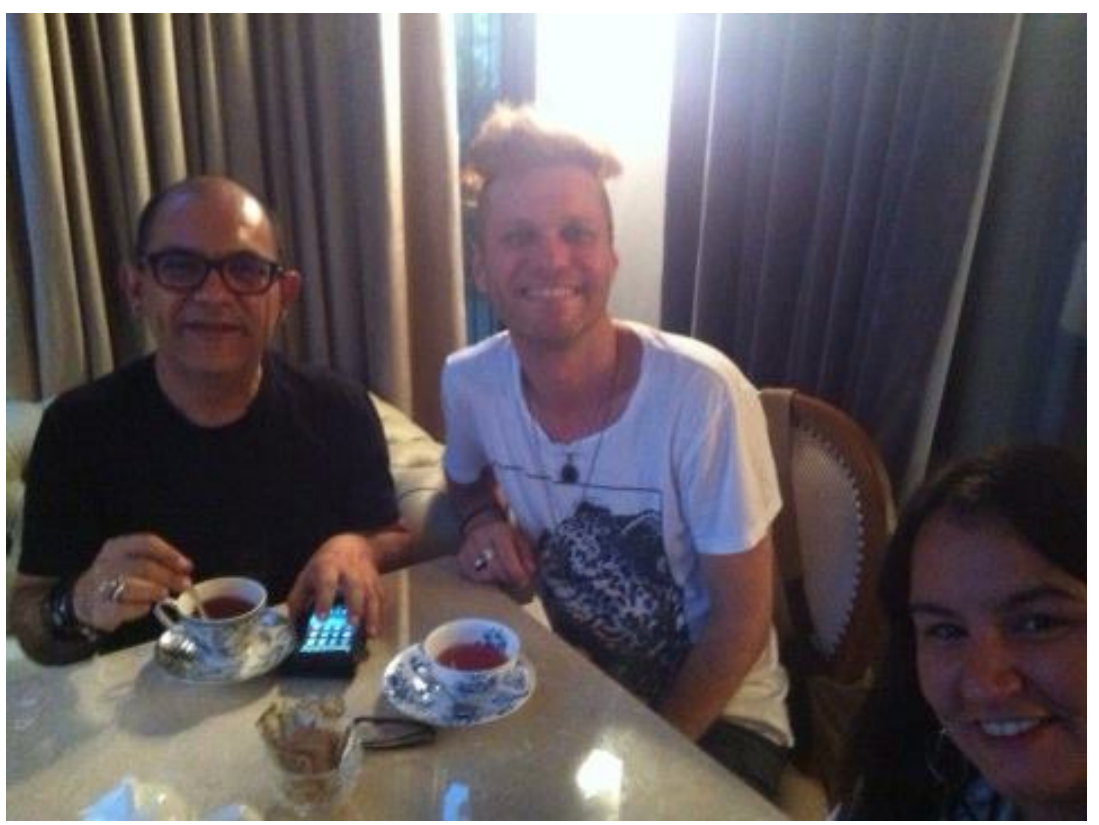

Durante os dias de convivência com Jociele Lampert, Lucimar Bello e Fábio Wosniak abrimos outras frentes de trabalho e fortalecemos nosso reencontro com John Dewey e sua obra com destaque para o livro Arte como Experiência. Estabelecemos uma agenda de trocas de ideias e chegamos a ler Estética da Professoralidade: um estudo crítico sobre a formação do professor do Marcos Villela Pereira (2013), porém meu engajamento na greve dos docentes das universidades estaduais do Ceará me impediu de manter uma sistemática de trabalho com o Fábio Wosniak e a Jociele Lampert.

Em julho de 2015 estive de volta a UDESC, a Florianópolis e, claro, me reencontrei com Jociele Lampert, Lucimar Bello e Maria Lucia Batezar, agora

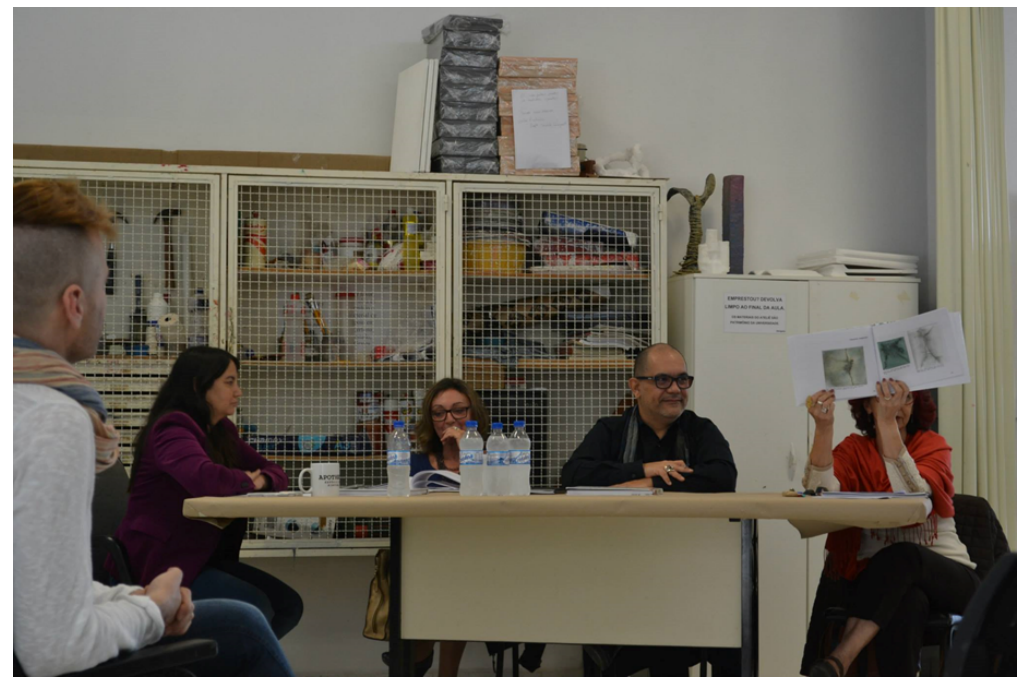




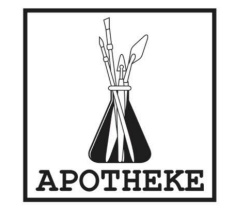

REVISTA APOTHEKE

ISSN 2447-1267

v.1, n.1, ano 1, 2015
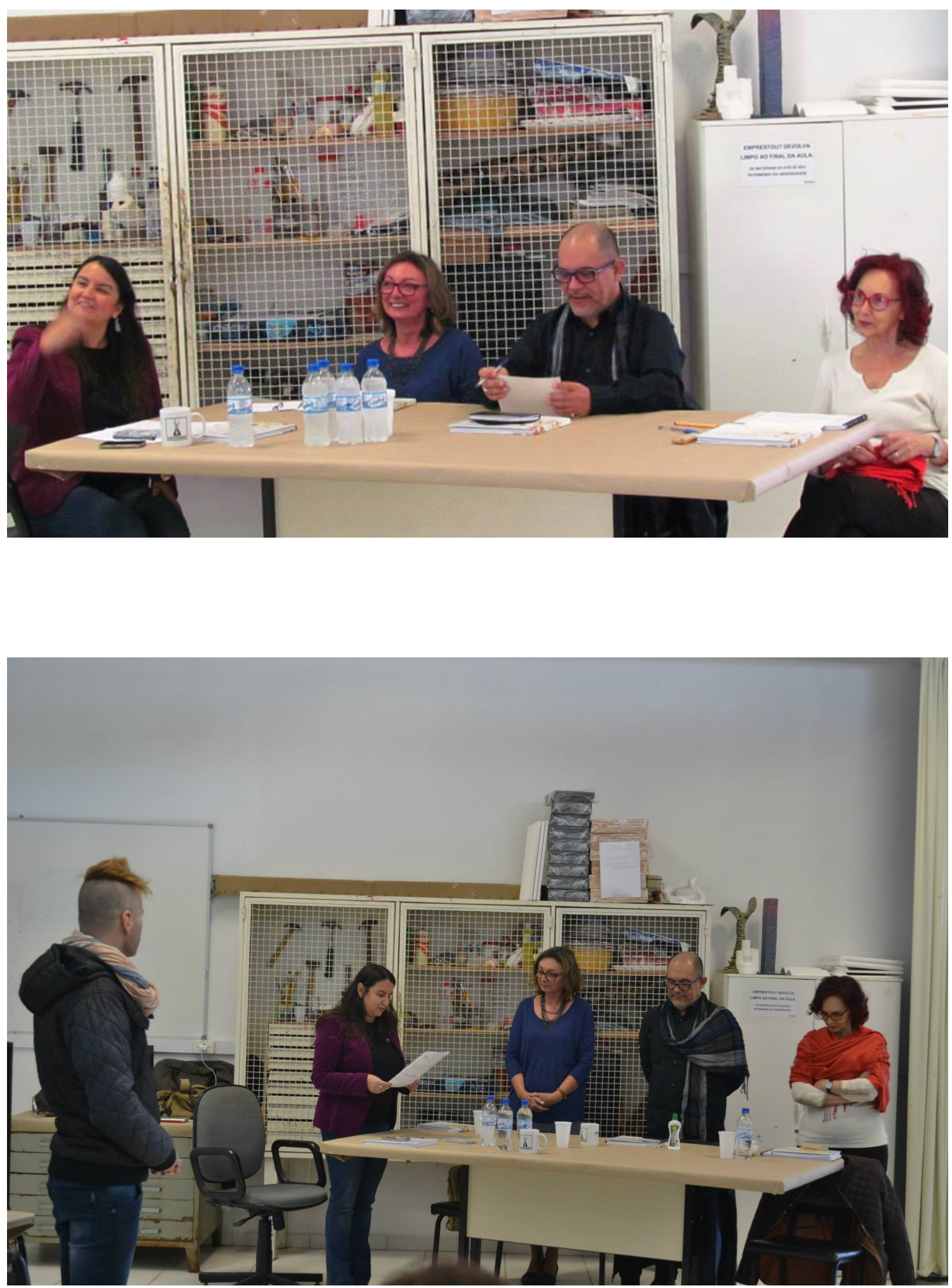
Esse retorno a Florianópolis, UDESC, Apotheke para a defesa de mestrado do Wosniak foi a oportunidade para conhecer mais do trabalho que a Jociele Lampert vem desenvolvendo com seus estudantes da graduação a pós-graduação, além de aproximar artistas da universidade e a universidade dos artistas.

Logo após a defesa tive dois importantes momentos com a Lampert, um quando no Apotheke falei sobre curadoria, sobre minha experiência como curador independente no Juazeiro do Norte e a outra quando em sua casa apresentou o trabalho vivido na pós-graduação com o projeto das revistas. Como falei para a Jociele na ocasião volto a confirmar agora: precisamos dar visibilidade aos processos de criação estético/artística que mediamos em nossas salas de aula, nossos grupos de pesquisa e assegurar que eles sejam mediadores do dentro para fora e do fora para dentro como estratégias de educação para além da titulação acadêmica. Não esperava que hoje estivesse fazendo este relato/memória para a publicação de uma Revista/Revistas organizada pela Jociele Lampert e seus estudantes e que conversamos sobre. Me sinto cúmplice e ao mesmo tempo membro do Apotheke uma vez que para nós artistas/professords/pesquisador@s não existem fronteiras que nos impeçam de compartrilhar. 